\title{
IDENTIFIKASI MOTIVASI PETANI DALAM MELAKUKAN USAHATANI TEMBAKAU DI KABUPATEN SITUBONDO
}

\section{THE IDENTIFICATION OF FARMER'S MOTIVATION IN CONDUCTING TOBACCO FARMING IN SITUBONDO}

\author{
Puryantoro*, Fathor Rozy \\ Fakultas Pertanian, Universitas Abdurachman Saleh Situbondo, \\ Jl. PB. Sudirman No. 07 Situbondo, Jawa Timur \\ *E-mail::puryantorounars@gmail.com \\ (Diterima 09-12-2019; Disetujui 14-01-2020)
}

\begin{abstract}
ABSTRAK
Tembakau merupakan tanaman perkebunan yang mempunyai nilai komersial. Motivasi petani sebagai pengelola usahatani diartikan sebagai kondisi yang mendorong petani untuk melakukan kegiatan usahatani, yaitu membudidayakan tanaman tembakau. Tujuan penelitian ini untuk mengidentifikasi motivasi petani dalam membudidayakan tanaman tembakau di Desa Suboh Kecamatan Suboh Kabupaten Situbondo. Sampel dengan teknik total sampling sebanyak 20 responden petani tembakau. Data dianalisa dengan menggunakan teknik regresi berganda dengan variabel umur, pendidikan, pengalaman, jumlah anggota keluarga, biaya produksi dan pendapatan. Hasil penelitian menunjukkan bahwa pendidikan, pengalaman dan jumlah keluarga mempengaruhi motivasi petani dalam budidaya tembakau yang ada di Desa Suboh.
\end{abstract}

Kata kunci: Motivasi, Petani, Tembakau

\section{ABSTRACT}

One of the plantation crops that have commercial value is tobacco. The motivation of farmers as farm managers is defined as a condition that encourages farmers to do farming activities, namely cultivating tobacco plants. This study identified factors that influence the motivation of farmers to grow tobacco in Suboh Village, Suboh Subdistrict, Situbondo Regency. The location of the study was determined purposively with a sample of 20 respondent. The data were analyzed by using multiple regression techniques with variables of age, education, experience, number of family members, production cost and income. The result showed that education, experience and number of families influenced the motivation of farmers in tobacco cultivation in Suboh Village.

Keywords: Motivation, Farmers, Tobacco

\section{PENDAHULUAN}

Usahatani tembakau memiliki peluang yang menjanjikan sebagai ladang pekerjaan tentunya dengan memperhatikan kelestarian lingkungan hidup untuk memenuhi kebutuhan pasar baik ditingkat regional, nasional dan internasional. Wibowo (2007) dalam (Soejono, 2012) menyatakan bahwa tembakau tidak akan tergantikan hingga ada tanaman yang dapat mempunyai nilai seimbang dengan industri tembakau.

Kabupaten Situbondo merupakan salah satu sentra produksi tembakau di 
wilayah eks-Karesidenan Besuki Jawa Timur. Komoditas tembakau merupakan komoditi bisnis yang mempunyai arti ekonomi yang cukup besar, pemerintah Kabupaten Situbondo menjadikannya sebagai komoditi unggulan daerah selain komoditas kopi. Daerah penghasil tembakau di Kabupaten Situbondo juga cukup banyak, sehingga komoditas tembakau di Kabupaten Situbondo cukup mudah didapatkan. Menurut data BPS
Situbondo bahwa tembakau mengalami kenaikan 9,37\% di tahun 2018.

Usahatani tembakau yang ada di Kabupaten Situbondo khususnya di daerah Suboh dilakukan pada saat musim kemarau sehingga varietas yang digunakan adalah varietas/ jenis tembakau besuki atau cerutu. Tabel 1 menunjukkan perkembangan luas area, produktivitas dan produksi tembakau di Kabupaten Situbondo.

Tabel 1. Luas Panen, Rata-rata Produksi, dan Total Produksi Tanaman Perkebunan di Kabupaten Situbondo Tahun 2016

\begin{tabular}{|c|c|c|c|c|}
\hline No & Tanaman & Luas Area (Ha) & Produktivitas Ton/Ha & Produksi (Ton) \\
\hline \multicolumn{5}{|c|}{ Tanaman Semusim } \\
\hline 1. & Tebu & 10.002 & 11,93 & 119.366 \\
\hline 2. & Tembakau & 3.981 & 600,18 & 2.389 .342 \\
\hline 3. & Jarak Pagar & 80 & - & - \\
\hline \multicolumn{5}{|c|}{ Tanaman Tahunan } \\
\hline 1. & Kelapa & 4.038 & 0,93 & 378,3 \\
\hline 2. & Kopi & 1.888 & 3,57 & 675,9 \\
\hline 3. & Cengkeh & 30 & 0,03 & 0,9 \\
\hline 4. & Jambu Mete & 19 & - & - \\
\hline 5. & Siwalan & 26 & 0,52 & 13,7 \\
\hline 6. & Asam Jawa & 107 & - & - \\
\hline
\end{tabular}

Sumber: BPS Kabupaten Situbondo, 2017

Jika dilihat dari Tabel 1, potensi komoditas tembakau di Kabupaten Situbondo pada tahun 2016 dengan luas area 3.981 ha dapat menghasilkan produksi 2.389.342 ton dan produktivitasnya mencapai 600,18 ton/ha. Di dalam survei pendahuluan, potensi lahan komoditas tembakau di Kabupaten Situbondo sesuai untuk budidaya tanaman tembakau karena berada pada daerah dataran rendah sehingga dapat menghasilkan produk yang berkualitas baik. Kebanyakan petani mengembangkan budidaya tembakau dengan memanfaatkan lahan yang kering karena tembakau ini tidak terlalu membutuhkan air yang cukup banyak.

Peningkatan produksi dan pendapatan merupakan tujuan dalam usahatani sehingga petani menjadi termotivasi untuk memperoleh keuntungan yang maksimal. Motivasi internal dan eksternal menjadi penentu 
keberhasilan usaha pertanian (Nisa, 2015).

Kegiatan yang mendorong petani untuk melakukan budidaya tanaman tembakau merupakan motivasi petani sebagai pengelola usaha.Hal ini menarik untuk dikaji karena meskipun banyak pilihan komoditas lainnya namun petani lebih memilih komoditas tembakau untuk dibudidaya. Tentu saja hal ini karena adanya dorongan motivasi petani dalam mengembangkan budidaya tembakau untukmenghasilkan pendapatan yang maksimal dari kegiatan usahatani budidaya tanaman tembakau. Tujuan penelitian ini untuk mengidentifikasi motivasi petani dalam membudidayakan tanaman tembakau di Desa Suboh Kecamatan Suboh Kabupaten Situbondo.

\section{METODE PENELITIAN}

Tempat penelitian ditentukan secara purposive method di Desa Suboh Kecamatan Suboh Kabupaten Situbondo. Desa Suboh menjadi pertimbangan lokasi penelitian karena Kecamatan Suboh memiliki produksi tembakau tertinggi sebanyak 864 ton dari 17 kecamatan di Kabupaten Situbondo (BPS Kabupaten Situbondo, 2018). Populasi sekaligus menjadi sampel penelitian sebanyak 20 petani tembakau.
Data dianalisa menggunakan analisis regresi linier berganda. Untuk analisis regresi linier berganda motivasi petani dalam membudidayakan tembakau adalah sebagai berikut (Sujarweni, V.Wiratna; Endrayanto, 2012):

$$
\begin{aligned}
Y= & a+b_{1} X_{1}+b_{2} X_{2}+b_{3} X_{3}+b_{4} X_{4}+ \\
& b_{5} X_{5}+b_{6} X_{6}+e
\end{aligned}
$$

Keterangan:

Y : Motivasi Petani

a : Konstanta

$b_{n}$ : Koefisien variabel independen

$\mathrm{X}_{1}$ : Umur,

$\mathrm{X}_{2}$ : Pendidikan

$\mathrm{X}_{3}$ : Pengalaman,

$\mathrm{X}_{4}$ : Jumlah Anggota Keluarga

$\mathrm{X}_{5}$ : Biaya Produksi

$\mathrm{X}_{6}$ : Pendapatan

e : Standard error

Data yang digunakan berupa data primer dan data sekunder. Data primer diperoleh melalui wawancara terhadap petani tembakau sebagai responden yang bisa memberikan gambaran mengenai budidaya tembakau berdasarkan kuesioner. Data sekunder diperoleh dari instansi yang berhubungan dengan penelitian, yaitu BPS Kabupaten Situbondo, Dinas Tanaman Pangan, Hortikultura dan Perkebunan.

\section{HASIL DAN PEMBAHASAN}

Hasil penelitian berdasarkan uji hipotesis secara parsial untuk mengetahui seberapa besar pegaruh dari variabel bebas yaitu umur $\left(\mathrm{X}_{1}\right)$, pendidikan $\left(\mathrm{X}_{2}\right)$, 
pengalaman $\left(\mathrm{X}_{3}\right)$, jumlah keluarga $\left(\mathrm{X}_{4}\right)$, biaya produksi $\left(\mathrm{X}_{5}\right)$ dan pendapatan $\left(\mathrm{X}_{6}\right)$ terhadap motivasi petani dalam budidaya tembakau (Y). Untuk $\mathrm{t}$ tabel dengan rumus $d f=n-1, d f=20-1=19(2,093)$. Adapun hasil perhitungan analisis regresi linier melalui SPSS. Tabel 2 menunjukkan hasil uji hipotesis.

Tabel 2. Hasil Uji t

\begin{tabular}{llrr}
\hline \multicolumn{3}{c}{ Coefficients } \\
\hline Model & & \multicolumn{1}{c}{$\mathrm{t}$} & \multicolumn{1}{c}{ Sig. } \\
\hline 1 & (Constant) & 13.156 & .000 \\
& Umur & -1.123 & .282 \\
& Pendidikan & 3.674 & .003 \\
& Pengalaman & 3.181 & .007 \\
& Jumlah Keluarga & 2.564 & .024 \\
& Biaya Produksi & .389 & .703 \\
& Pendapatan & 2.007 & .066 \\
\hline
\end{tabular}

Sumber: Data penelitian diolah (2018)

Uji t untuk mengetahui variabel apa saja yang mempengaruhi motivasi dalam budidaya tembakau sebagai berikut:

a) Pengaruh umur terhadap motivasi petani dalam budidaya tembakau di Desa Suboh. Dari hasil analisis untuk variabel umur diperoleh $\mathrm{t}$ hitung sebesar $-1,123$ (nilai $\mathrm{t}$ hitung $<\mathrm{t}$ tabel $=-1,123<2,093)$ dengan probabilitas 0,282. Nilai probabilitas lebih besar dari 0,05 , menunjukan bahwa nilai $\mathrm{t}$ yang diperoleh tersebut tidak signifikan, artinya variabel umur $\left(\mathrm{X}_{1}\right)$ tidak berpengaruh secara signifikan terhadap motivasi petani dalam budidaya tembakau di Desa Suboh (Y).
Hal tersebut dapat disimpulkan bahwa t hitung $(-1,123)$ berada pada daerah Ho diterima/daerah penerimaan $\mathrm{Ho}$ maka keputusannya adalah tidak terdapat pengaruh yang positif dan signifikan umur terhadap motivasi petani dalam budidaya tembakau. Tidak berpengaruhnya umur terhadap motivasi petani dalam budidaya tembakau adalah apabila jumlah umur meningkat sebanyak 1 tahun maka motivasi petani dalam budidaya tembakau akan menurun sebesar 1 poin.

b) Pengaruh pendidikan terhadap motivasi petani dalam budidaya tembakau di Desa Suboh dari hasil analisis t hitung sebesar 3,674 (nilai t hitung $>\mathrm{t}$ tabel $=3,674>2,093$ ) dengan probabilitas 0,003 . Nilai probabilitas kurang dari 0,05, menunjukan nilai $\mathrm{t}$ yang diperoleh signifikan, artinya variabel pendidikan $\left(\mathrm{X}_{2}\right)$ berpengaruh secara signifikan terhadap motivasi petani dalam budidaya tembakau di Desa Suboh (Y).

t hitung $(3,674)$ berada pada daerah Ho ditolak/daerah penolakan Ho maka keputusannya adalah terdapat pengaruh positif dan signifikan pendidikan terhadap motivasi petani 
dalam budidaya tembakau. Berpengaruhnya pendidikan terhadap motivasi petani melakukan budidaya tembakau adalah apabila tingkat pendidikan meningkat sebanyak 1 tahun maka motivasi petani dalam budidaya tembakau akan meningkat juga sebesar 1 poin.

c) Pengaruh pengalaman terhadap motivasi petani dalam budidaya tembakau di Desa Suboh dari hasil analisis variabel pengalaman diperoleh nilai $\mathrm{t}$ hitung 3,181 (nilai $\mathrm{t}$ hitung $>\mathrm{t}$ tabel $=3,181>2,093)$ dengan probabilitas 0,007 . Probabilitas kurang dari 0,05 , menunjukan nilai $\mathrm{t}$ signifikan, berarti variabel pengalaman $\left(\mathrm{X}_{3}\right)$ berpengaruh secara signifikan terhadap motivasi petani dalam budidaya tembakau di Desa Suboh (Y).Nilai $\mathrm{t}$ hitung $(3,181)$ berada pada daerah Ho ditolak/daerah penolakan Ho maka keputusannya adalah terdapat pengaruh positif dan signifikan pengalaman terhadap motivasi petani melakukan budidaya tembakau. Berpengaruhnya pengalaman terhadap motivasi petani dalam budidaya tembakau adalah apabila tingkat pengalaman meningkat sebanyak 1 tahun maka motivasi petani dalam budidaya tembakau akan meningkat juga sebesar 1 poin.

d) Pengaruh jumlah keluarga terhadap motivasi petani dalam budidaya tembakau di Desa Suboh dari hasil analisis variabel jumlah keluarga didapatkan nilai t hitung sebesar 2,564 (nilai $\mathrm{t}$ hitung $>\mathrm{t}$ tabel $=2,564>$ 2,093) dengan probabilitas 0,024. Nilai probabilitas kurang dari 0,05, menunjukan nilai $\mathrm{t}$ yang tersebut signifikan, artinya variabel jumlah keluarga $\left(\mathrm{X}_{4}\right)$ berpengaruh secara signifikan terhadap motivasi petani dalam budidaya tembakau di Desa Suboh (Y).

Hal tersebut dapat disimpulkan bahwa t hitung (2,564) berada pada daerah Ho ditolak/daerah penolakan Ho maka keputusannya adalah terdapat pengaruh yang positif dan signifikan jumlah keluarga terhadap motivasi petani melakukan usahatani budidaya tembakau. Berpengaruhnya jumlah keluarga terhadap motivasi petani dalam budidaya tembakau adalah apabila jumlah keluarga meningkat sebanyak 1 orang maka motivasi petani dalam budidaya tembakau akan meningkat juga sebesar 1 poin.

e) Pengaruh biaya produksi terhadap motivasi petani dalam budidaya tembakau di Desa Suboh dari hasil 
analisis variabel biaya produksi $\mathrm{t}$ hitung sebesar 0,389 (nilai $\mathrm{t}$ hitung $<\mathrm{t}$ tabel $=0,389<2,093)$ dengan probabilitas 0,703 . Karena nilai probabilitas lebih besar dari 0,05, menunjukan nilai t tidak signifikan, artinya bahwa variabel biaya produksi $\left(\mathrm{X}_{5}\right)$ tidak berpengaruh secara signifikan terhadap motivasi petani dalam budidaya tembakau di Desa Suboh (Y).

Hal tersebut dapat disimpulkan bahwa t hitung $(0,389)$ berada pada daerah Ho diterima/daerah penerimaan Ho maka keputusannya adalah biaya produksi tidak berpengaruh positif dan signifikan terhadap motivasi petani dalam budidaya tembakau. Tidak berpengaruhnya biaya produksi terhadap motivasi petani dalam budidaya tembakau adalah apabila jumlah biaya produksi meningkat sebanyak Rp 1.000 maka motivasi petani dalam budidaya tembakau akan menurun sebesar 1 poin.

f) Pengaruh pendapatan terhadap motivasi petani dalam budidaya tembakau di Desa Suboh dari analisis variabel pendapatan dihasilkan $\mathrm{t}$ hitung 2,007 (nilai $\mathrm{t}$ hitung $<\mathrm{t}$ tabel $=$ $2,007<2,093)$ dengan probabilitas 0,066. Nilai probabilitas yang lebih besar dari 0,05 , menunjukkan nilai $\mathrm{t}$ tidak signifikan, artinya variabel pendapatan $\left(\mathrm{X}_{6}\right)$ tidak berpengaruh secara signifikan terhadap motivasi petani dalam budidaya tembakau di Desa Suboh (Y).

Hal tersebut dapat disimpulkan bahwa t hitung $(2,007)$ berada pada daerah Ho diterima/daerah penerimaan $\mathrm{Ho}$ maka keputusannya adalah pendapatan petani tidak berpengaruh positif dan signifikan terhadap motivasi petani dalam budidaya tembakau. Tidak berpengaruhnya pendapatan terhadap motivasi petani dalam budidaya tembakau adalah apabila jumlah pendapatan meningkat sebanyak Rp. 1.000,- maka motivasi petani dalam budidaya tembakau akan menurun sebesar 1 poin.

Berdasarkan uji parsial tersebut maka pendidikan, pengalaman dan jumlah keluarga yang mempengaruhi motivasi petani dalam budidaya tembakau yang ada di Desa Suboh, sebab faktor pendidikan, pengalaman dan jumlah keluarga merupakan faktor internal yang dimiliki petani dalam meningkatkan motivasi untuk melakukan usahatani tembakau sehingga keinginan petani untuk memperoleh keuntungan yang lebih besar akan semakin tinggi. 
Hasil penelitian (Kusuma, Basuki, \& Sriyoto, 2015) dan (Reflis, Nurung, \& Pratiwi, 2011) juga menyimpulkan bahwa tanggungan keluarga tidak ada hubungannya dengan motivasi petani. Banyaknya jumlah tanggungan keluarga memicu kepala keluarga bekerja lebih keras untuk memenuhi kebutuhan keluarga sehingga keinginan menambah penghasilan sangat mempengaruhi petani untuk terus mengusahatanikan tembakau. Pada kondisi keluarga yang mempunyai anggota keluarga lebih banyak maka pengeluaran untuk memenuhi kebutuhan hidup akan semakin tinggi, hal ini akan memicu keinginan untuk mendapatkan penghasilan tambahan. Biaya hidup yang semaikin tinggi karena harga kebutuhan bahan primer yang semakin naik dari waktu kewaktu menjadi salah satu motivasi petani untuk melakukan budidaya tembakau karena menganggap tembakau mempunyai prospek untuk diusahakan sebagai sumber pendapatan.

Menurut (Herminingsih, 2014), pendidikan formal dan pengalaman mempengaruhi secara positif dan signifikan terhadap perilaku petani. Keberanian pengambilan risiko terjadi pada petani yang memiliki tingkat pendidikan dan pengalaman yang tinggi. Dengan pengalaman petani dapat melihat peluang dan kendala yang dihadapi dalam usahatani tembakau. Hasil penelitian ini bertolak belakang dengan penelitian (Ardi, MR; Effendi, 2018) bahwa motivasi tidak dipengaruhi secara nyata oleh pendidikan.

\section{KESIMPULAN DAN SARAN}

\section{Kesimpulan}

Hasil analisa disimpulkan bahwa motivasi petani dalam budidaya tembakau secara dipenagruhi oleh variabel tingkat pendidikan, pengalaman dan jumlah keluarga. Motivasi petani tembakau tidak dipengaruhi oleh variabel umur, biaya produksi dan pendapatan.

\section{Saran}

Berdasarkan kesimpulan penelitian, maka diajukan saran sebagai berikut:

1. Membentuk koperasi petani tembakau untuk memotong rantai pemasaran yang tidak menguntungkan petani.

2. Melakukan kegiatan kerjasama dengan lembaga terkait dalam rangka pengembangan usahatani tembakau. Kerjasama yang dilakukan bisa melalui kerjasama teknologi dan informasi dengan pihak penyuluh pertanian maupun kerjasama pemasaran hasil produksi dengan 
pihak parusahaan maupun pabrik yang memerlukan bahan baku tembakau dalam proses produksinya

\section{DAFTAR PUSTAKA}

Ardi, MR; Effendi, M. (2018). Faktorfaktor yang Memotivasi Petani Dalam Melakukan Usahatani Semangka (Citrullus Vulgaris S.) di Desa Sumber Sari Kecamatan Kota Bangun Kabupaten Kutai Kartanegara. Jurnal Agribisnis dan Komunikasi Pertanian (Journal of Agribusiness and Agricultural Communication), $1(2), \quad 98$. https://doi.org/10.35941/akp.1.2.20 18.1709.98-103

BPS Kabupaten Situbondo. (2018). Kabupaten Situbondo Dalam Angka Tahun 2018. Retrieved from https://situbondokab.bps.go.id/publi cation

Herminingsih, H. (2014). Pengaruh perubahan iklim terhadap perilaku petani tembakau di kabupaten jember. Jurnal Matematika, Saint, Teknologi, 5(2), 42-51.
Kusuma, A. P., Basuki, S. P., \& Sriyoto. (2015). Seluma: The Factors That Related to Motivation in Saving The Harvest of Farmers in Seluma. Agrisep, 14(1), 108-119.

Nisa, N. K. (2015). Motivasi Petani dalam Menanam Komoditas pada Daerah Lumbung Padi Di Kabupaten Gresik. Swara Bhumi, 3(3), 80-90.

Reflis, ., Nurung, M., \& Pratiwi, J. D. (2011). Motivasi Petani Dalam Mempertahankan Sistem Tradisional Pada Usahatani Padi Sawah Di Desa Parbaju Julu Kabupaten Tapanuli Utara Propinsi Sumatera Utara. Jurnal AGRISEP, 10(1), 51-62. https://doi.org/10.31186/jagrisep.10 .1.51-62

Soejono, D. (2012). Kajian Respon Petani Terhadap Budidaya Tembakau dan Pasca Panen di Kabupaten Sidoarjo. Universitas Jember, 6(1), 61-69. Retrieved from

https://jurnal.unej.ac.id/index.php/J SEP/article/view/803

Sujarweni, V.Wiratna; Endrayanto, P. (2012). Statistika untuk Penelitian. Yogyakarta: Graha Ilmu. 